\title{
Comunicación entre bacterias: el WhatsApp de Pseudomonas aeruginosa
}

\author{
Sharel Pamela Díaz Pérez y Jesús Campos García
}

\section{Resumen}

La comunicación se basa en un intercambio de información por medio de un lenguaje queva de un emisor hacia un receptor. Éste recibe el mensaje y puede o no emitir alguna respuesta en un determinado contexto. Actualmente, es posible establecer una comunicación sencilla, eficaz y rápida sin importar la distancia, ya que se cuenta con herramientas tecnológicas como dispositivos móviles que utilizan aplicaciones como WhatsApp, Facebook Messenger, Twitter, entre otras. Las bacterias tienen un sistema de comunicación muy similar a WhatsApp, conocido como Quorum Sensing (QS, percepción de cuórum). En este artículo se relatarán las semejanzas entre estos sistemas, pues diversas investigaciones han determinado al qs como un tipo de comunicación célula-célula, el cual desempeña un papel clave en la regulación de la expresión de genes de virulencia, en un sin número de patógenos bacterianos, ya que se producen y liberan pequeñas señales químicas conocidas como autoinductores, semejantes al lenguaje cibernético. Se ha visto que la bacteria patógena de humanos Pseudomonas aeruginosa utiliza este tipo de comunicación para modular la producción de factores de virulencia, lo que le permite provocar infecciones agudas y crónicas, en individuos inmunocomprometidos y en pacientes con fibrosis quística, lo que ocasiona que estas infecciones sean difíciles de erradicar con la administración de antibióticos convencionales. Por ello, es de suma importancia entender el papel del "WhatsApp" de la comunicación bacteriana, ya sea en individuos infectados o como mecanismo de control antibacteriano.

Palabras clave: quorum sensing, percepción de cuórum, comunicación bacteriana, virulencia, infecciones, bioluminiscencia.

\section{Communication between bacteria: Pseudomonas aeruginosa's WhatsApp}

\begin{abstract}
Communication is based on an exchange of information using a language, that goes from a sender to a receiver, which receives the message and can —or not — send some response in a determined context. Currently, it is possible to establish simple, efficient, and fast communication regardless of distance, since existing technological tools, such as mobile devices, use applications such as WhatsApp, Facebook Messenger, Twitter, and others. The bacteria have a communication system similar to WhatsApp, known as Quorum Sensing (QS). In this article, the similarities between these communication systems will be described. Several investigations have determined that Qs is a type of cell-cell communication that plays a key role in regulation of virulence gene expression in different bacterial pathogens, due to the fact that it produces and releases small chemical signals called "autoinducers", and that these are similar to cybernetic language. The human pathogenic bacterium Pseudomonas aeruginosa has been described to use this type of communication to modulate the production of virulence factors, provoking acute and chronic infections in immunocompromised persons and cystic fibrosis patients, causing infections to be difficult to eradicate with the supply of conventional antibiotics. Thus, it is important to understand the bacterial communication "WhatsApp" as an antibacterial control mechanism in infected individuals.
\end{abstract}

Keywords: quorum sensing, bacterial communication, infections, bioluminescence.

Recepción: 04/08/2020. Aprobación: 22/02/2021. Dol: http://doi.org/10.22201/cuaieed.16076079e.2021.22.3.7 


\section{Sharel Pamela Díaz Pérez}

$$
\begin{aligned}
& \text { diazp.qfb@gmail.com } \\
& \text { orcid.org/0000-0001-5921-575X }
\end{aligned}
$$

Maestra en Ciencias en Biología Experimental, Instituto de Investigaciones Químico-Biológicas, Universidad Michoacana de San Nicolás de Hidalgo (॥QB-UMSNH). Estudiante de Doctorado del Programa Institucional de Doctorado en Ciencias Biológicas (PIDCB), opción Biología Experimental, Instituto de Investigaciones Químico-Biológicas, Universidad Michoacana de San Nicolás de Hidalgo.

\section{Jesús Campos García}

$$
\begin{aligned}
& \text { jesus.campos@umich.mx } \\
& \text { orcid.org/0000-0002-8337-5830 }
\end{aligned}
$$

Doctor en Biotecnología, Instituto de Biotecnología, Universidad Nacional Autónoma de México (UnAm). Profesor-Investigador Titular del Laboratorio de Biotecnología Microbiana del Instituto de Investigaciones Químico Biológicas de la Universidad Michoacana de San Nicolás de Hidalgo (IIQB-UMSNH). Es miembro de la Academia Mexicana de Ciencias A.C. (AMC) y del Sistema Nacional de Investigadores (nivel ॥). Premio Nacional de Investigación en Ciencias Naturales-2008 por la AMc, Premio Estatal de Investigación Científica y Humanística 2009 (Gobierno del Estado de Michoacán), inventor de la primera patente de la UMSNH (2009), actualmente posee 4 títulos de patentes. Su trabajo de investigación trata sobre los mecanismos de interacción de Pseudomonas aeruginosa en el ambiente: mecanismos de degradación, biocombustibles, interacción huésped-patógeno y metabolitos con potencial biotecnológico. 


\section{Introducción}

Desde el origen de las civilizaciones, la comunicación entre individuos es un proceso indispensable para transmitir información e intercambiar ideas para desarrollar potencialidades. Este fenómeno tan cotidiano es importante tanto para seres humanos, plantas, animales, como para los microorganismos, para llevar a cabo funciones biológicas, tales como sobrevivir, adaptarse, crecer, reproducirse, etcétera.

Actualmente, se utilizan herramientas tecnológicas en tiempo real para la comunicación entre seres humanos, como el teléfono celular, con múltiples aplicaciones o apps. Tal es el caso de WhatsApp, una de las aplicaciones más populares, ya que es utilizada a nivel mundial por millones de personas. Por otro lado, los microorganismos unicelulares procariotas llamadas bacterias, han utilizado mecanismos de comunicación para poder reproducirse, emitir luz, incluso generar infecciones a humanos, animales y plantas (ver imagen 1).

Imagen 1. El WhatsApp de Pseudomonas aeruginosa. Adaptación del logo de WhatsApp.

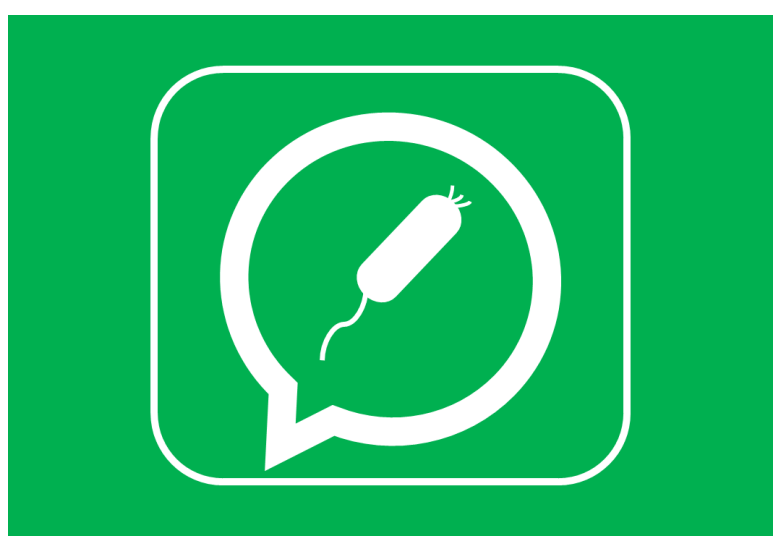

Una de las bacterias que posee un mecanismo de comunicación entre ellas es la especie de Pseudomonas aeruginosa. Esta bacteria en humanos es patógena y oportunista, causa infecciones de vías respiratorias, lo que afecta el sistema respiratorio e inmunológico del hospedero, en el que la regulación de la comunicación entre sí está asociada con la producción de múltiples factores de virulencia, que influyen en la colonización y patogenicidad (Lee y Zhang, 2015). Este sistema de comunicación bacteriano se denomina censado o percepción de cuórum (quorum sensing, QS), y es un mecanismo que regula la producción de factores de virulencia, los cuales son esenciales en la infección en humanos, animales y/o plantas, y, por lo tanto, en su patogenicidad.

\section{Érase una vez, hace 41 años}

El sistema de comunicación celular, QS, fue descubierto en dos especies bacterianas que viven en el mar, Vibrio fischeri y Vibrio harveyi, debido a que en ambas se observó emisión de luz. Ésta es observada en las playas Ilamadas bioluminiscentes, como Holbox en el caribe mexicano (ver video 1). Dicha emisión de luz es producida por organismos dinoflagelados, las cuales son algas que viven en el fondo del mar y que contienen dos largas colas Ilamadas flagelos, que a su vez tienen enzimas denominadas luciferasas (producen luminiscencia). Esta 
Video 1. Bioluminiscencia en playas (El rincón curioso, 2018). característica, naturalmente es utilizada por los organismos para confundir a sus depredadores, atraer pareja e incluso comunicarse. Existen microorganismos patógenos que utilizan este mecanismo para la comunicación, como son Vibrio cholera, Pseudomonas aeruginosa, entre otras (Papenfort y Bassler, 2016).

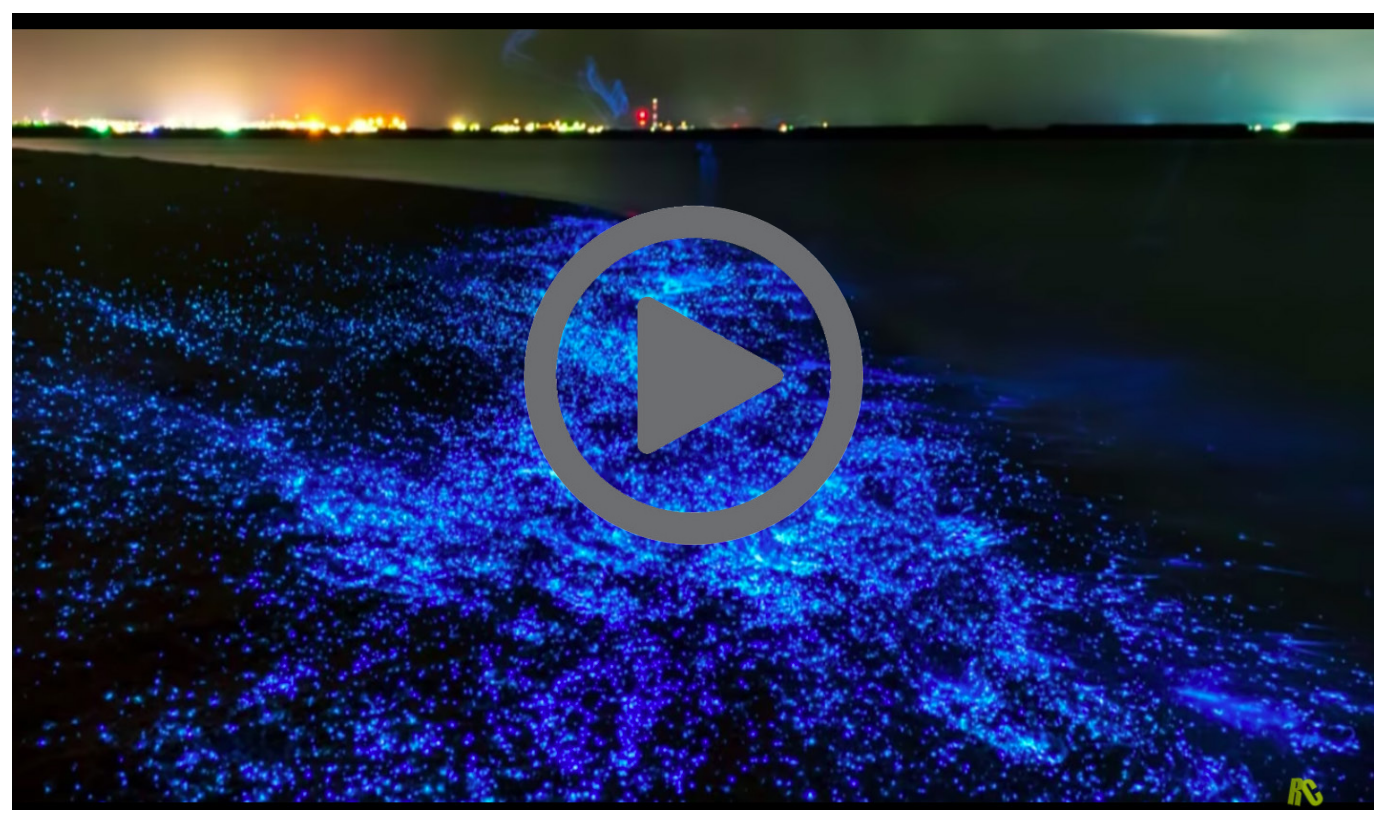

\section{Los creadores y administradores del grupo QS de Pseudomonas aeruginosa}

La percepción o censado de cuórum (quorum sensing, Qs) es un mecanismo de regulación de la expresión genética en respuesta a la densidad de la población celular, es decir, es el fenómeno que ocurre cuando existe un aumento de la población bacteriana y en consecuencia modifica la expresión de genes para activar mecanismos de control poblacional. Ahora bien, uno de los microorganismos en los que más se ha estudiado el os es Pseudomonas aeruginosa (ver imagen 3), debido a que es una de las bacterias que causa infecciones durante la hospitalización de pacientes con un sistema inmunológico deficiente. $P$. aeruginosa pertenece al grupo de las bacterias gram negativas, tiene forma de bacilo (cilindro) y en medios de cultivo genera cierta coloración verde-azul, proporcionada por compuestos fenazínicos, llamados piocianina y pioverdina (Moradali et al., 2017). Además, es considerada como una de las bacterias más patógena en humanos, debido a que no existe un tratamiento efectivo que permita matarla por completo. Asimismo, se ha visto que el os es un importante mecanismo de comunicación en esta bacteria, que le permite a evadir el sistema inmunológico y, por consiguiente, infectar principalmente pulmones, entre otros órganos (Papenfort y Bassler, 2016). 
Imagen 2. Pseudomonas aeruginosa. Fuente: Oosthuizen, 2013.

${ }^{1}$ Es el proceso cuando se realiza una copia de una secuencia perteneciente a un gen del DNA en una molécula de RNA, usando está información se puede produce una proteína. Síntesis de RNA mensajero: Es el proceso en el cual se genera una molécula de RNA de cadena sencilla a nivel transcripcional.

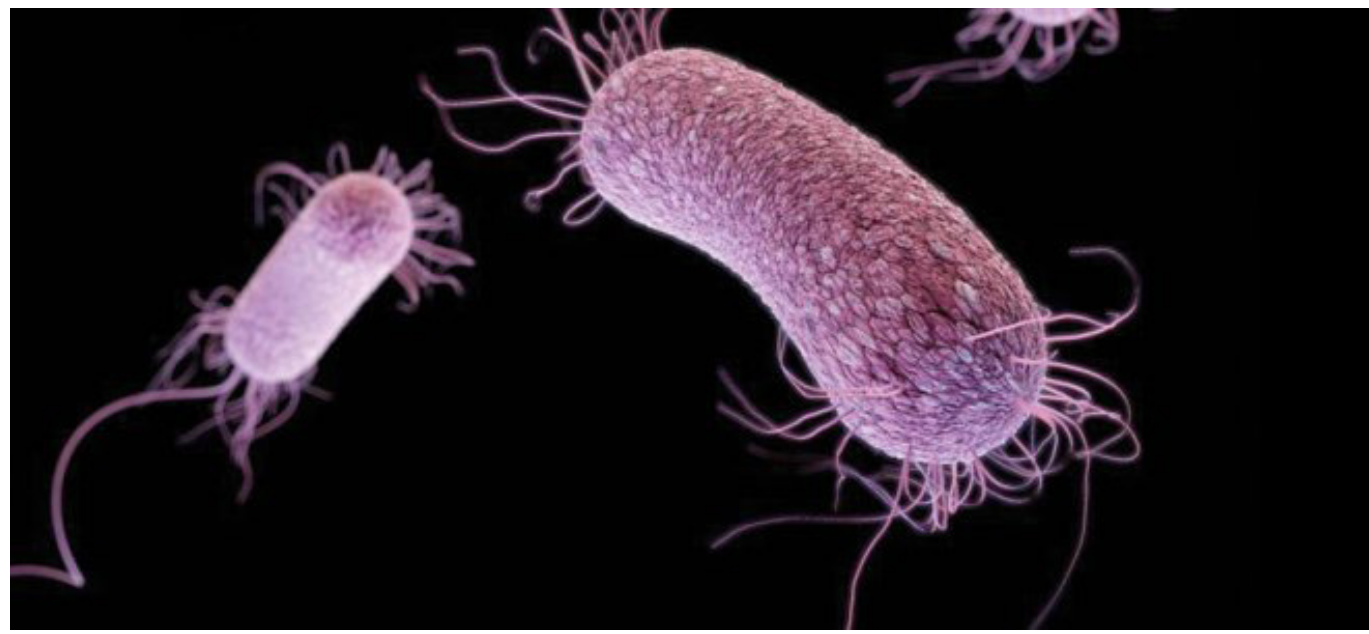

Actualmente, ha sido estudiado el mecanismo por el cual se da el os en $P$. aeruginosa. Ahora bien, este tipo de comunicación bacteriana es muy similar a cuando creamos un grupo de WhatsApp con amigos o familiares. Dentro de los participantes del grupo en la comunicación de $P$. aeruginosa se encuentran moléculas denominadas autoinductores, los cuales son las señales químicas o los tipos de mensajes que produce y utiliza. Cuando incrementa la densidad poblacional bacteriana, estas moléculas señal se acumulan, es decir, se inicia la escritura de uno o múltiples mensajes en este WhatsApp, lo que ocasiona la activación de ciertas rutas de señalización en la bacteria, que a su vez activarán la expresión génica, es decir, se emite una respuesta al mensaje para iniciar una conversación entre el grupo de WhatsApp. Como consecuencia, los principales genes que se activan a nivel transcripcional (síntesis de RNA mensajero) ${ }^{1}$ son los que codifican para la producción de factores de virulencia y, de este modo, se ocasionan enfermedades al portador de la bacteria.

Existen cuatro administradores de esta comunicación, los cuales se establecen de manera jerárquica, pero se relacionan entre sí, y contribuyen o no al desarrollo de la comunicación. El primer administrador implicado es el sistema las, un segundo es el sistema rhl, el tercero es pqs y el cuarto administrador es el iqs (Lee y Zhang, 2015). Cada administrador sugiere la presencia de ciertos contactos o participantes para emitir una señal, ya sea, en relación con WhatsApp, un mensaje, sticker o gif hacia la conversación, dependiendo de la situación en la que se encuentre.

\section{Los participantes del grupo del "WhatsApp" de Pseudomonas aeruginosa}

Inicialmente, para que cada participante del grupo emita un mensaje, señal, sticker o gif son necesarios varios componentes adicionales. En primera instancia, como se muestra en la imagen 3, el que puede comenzar con la creación de una 
conversación, o el inicio del Qs, es el sistema las, que comienza a generar un mensaje cuando la enzima Lasl produce la molécula señal N-3-oxododecanoilhomoserina lactona $(\mathrm{OdDHL})$. Cuando ésta se genera a una determinada concentración, como escribir palabras y preguntas hasta completar un mensaje, se une con su regulador transcripcional (LasR), el cual funciona como un generador de conversación en el grupo de "WhatsApp", siendo de esta manera capaz de enviar el mensaje a la conversación. Posteriormente, los administradores rh/y pqs entrarán a la conversación. Con lo cual, rh/ entra en actividad (o en línea) y, de la misma manera que el administrador las, su enzima Rhll produce su autoinductor o molécula señal N-butirilhomoserina lactona (BHL) (Ahator y Zhang, 2019). Al generarse acumulación de estas moléculas señal, a similitud en una conversación, se generan los mensajes y estos se unen al modulador de la conversación (RhIR); el cual, a su vez, evitará el envío del mensaje al sistema pqs (por sus siglas en inglés,

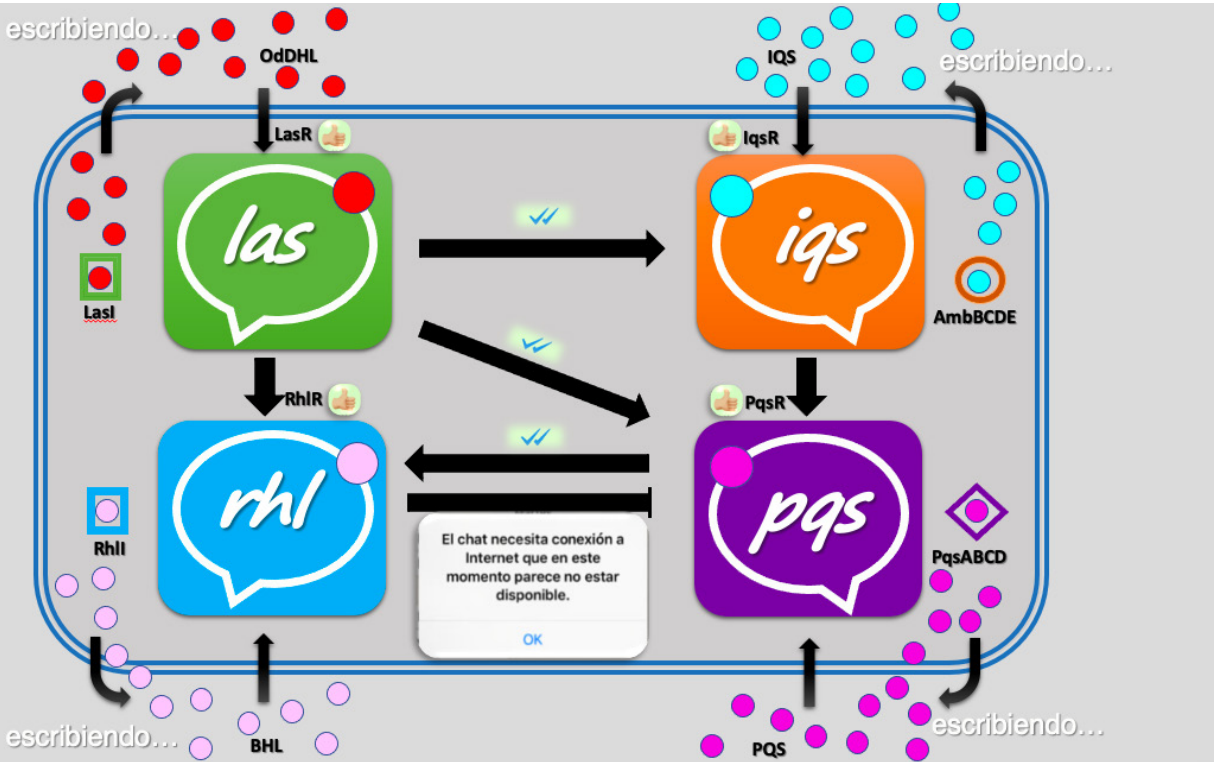
Pseudomonas Quinolone Signal). RhIR actúa como un moderador dentro del grupo para que no se generen controversia o saturación de mensajes, ya que pqs es el participante que reenvía mensajes no deseados, tales como videos o cadenas que no son útiles para la comunicación. Cabe destacar que los sistemas las y $r$ / fueron los primeros en descubrirse y son los sistemas clave involucrados en la regulación de procesos fisiológicos, así como la virulencia de $P$. aeruginosa. Sin embargo, el sistema las es la cabeza del

Imagen 3. La comunicación por WhatsApp de Pseudomonas aeruginosa. Adaptación de circuito de Lee y Zhang, 2015. grupo a nivel jerárquico, por lo que le correspondería ser considerado como el creador del "WhatsApp" utilizado por la bacteria P. aeruginosa. Asimismo, el tercer sistema pqs, inducido a mensajear por el modulador de conversaciones las, retroalimenta la conversación para activar a los participantes del grupo, como a rhl y conectar así con los 3 módulos de señalización; por lo que éste actúa como el participante "zen" en este grupo, o bien el que siempre desea los buenos días a todos los integrantes y llena de stickers el grupo de WhatsApp. El sistema pqs selecciona stickers a través de un grupo de genes conocidos como PqsABCD, gracias a la participación de su autoinductor denominado PQs (2-heptil3-hidroxi-4(1H)-Quinolona) (Ahator y Zhang, 2019). Finalmente, existe una cuarta señal que actúa en caso de que exista un ambiente de estrés, para generar un ambiente armónico, proporcionando la "buena vibra", iqs, donde las enzimas AmbBCDE son las generadoras de la molécula señal IQs [2-(2-hidroxifenil) tiazol4-Carbaldehído] al unirse a su moderador IqsR (Lee et.al., 2013). 


\section{Las funciones del "WhatsApp" de Pseudomonas aeruginosa}

Ahora bien, es importante conocer las consecuencias de esta comunicación de "WhatsApp" en P. aeruginosa. Una de las funciones más importantes que ejerce el principal administrador de este circuito, las, es generar mecanismos para crecer y multiplicarse, de tal forma que crean una red de comunicación tan grande que, en conjunto, es esencial para el proceso de infección bacteriana en cualquier órgano o tejido del individuo; este fenómeno en la ciencia es denominado formación/producción de biopelículas microbianas.

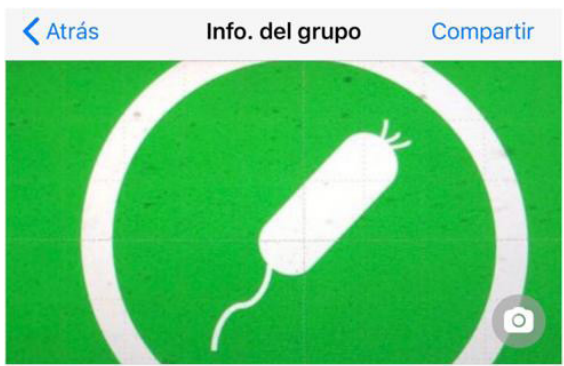

Quorum sensing

Producir factores de virulencia para producir daño al hospedero y regular producción de antibióticos, bioluminiscencia, asi como compuestos de interés biotecnologico y terapéutico

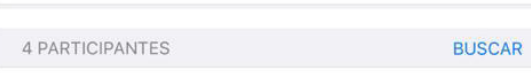

$+\quad$ Añadir participantes

es Enlace de invitación del grupo

(las) Tú

(iq5) iqs

(pas) pqs

(mi) $\mathrm{rhl}$

Exportar chat

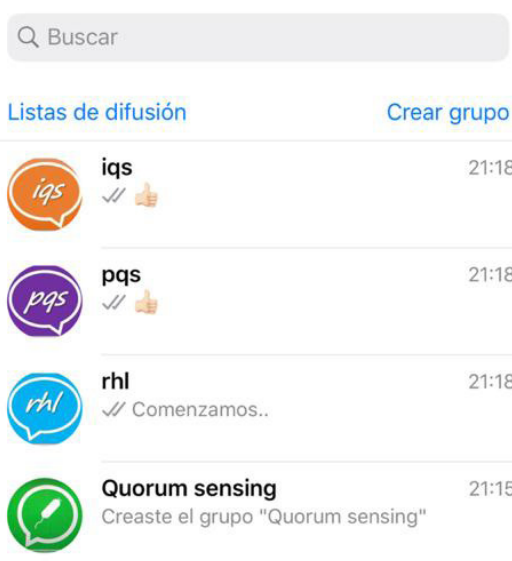

\section{Chats}
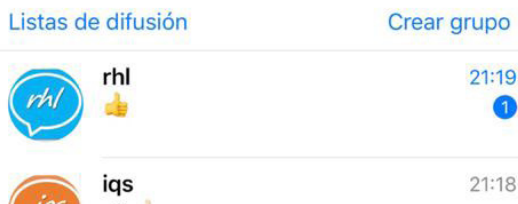

pas pqs

IV

Quorum sensing

Creaste el grupo "Quorum sensing"
Por otro lado, el sistema $\mathrm{rh} /$ regula la producción de enzimas y componentes celulares que favorecen el establecimiento de la infección, con lo que se llegan a destruir tejidos. Asimismo, el sistema pqs se encarga de modular la producción tanto de biopelículas microbianas como de un compuesto que es utilizado para evadir el sistema inmunológico y que ocasiona la coloración azul-verde característica de la bacteria $P$. aeruginosa cuando es crecida en medios de cultivo, denominado piocianina (Moradali et al., 2017). Éstas son algunas de las consecuencias que se generan de este grupo de WhatsApp para regular la producción de factores de virulencia, asociados con la patogenicidad de esta bacteria durante los procesos de infección para el ser humano. Sin embargo, no toda la regulación de esta comunicación tiene como consecuencia ejercer algún daño. Estos administradores de grupos de "WhatsApp" en otras bacterias regulan también la producción de antibióticos, bioluminiscencia, así como la síntesis de compuestos de interés biotecnológico y terapéutico.
Imagen 4. Grupo de "WhatsApp" de Pseudomonas aeruginosa.

\section{Conclusiones}

La comunicación bacteriana es tan importante como la comunicación que generamos en las redes sociales y aplicaciones como WhatsApp. Como podrás darte cuenta, dicha comunicación es necesaria para la bacteria de $P$. aeruginosa en el control/modulación de la producción de factores de virulencia, que favorecen las infecciones microbianas en humanos, animales y plantas. Sin embargo, no todo lo generado en esta comunicación o grupo de "WhatsApp" es 
dañino; por el contrario, también se pueden generar moléculas benéficas que ayuden a combatir ciertas enfermedades, como el cáncer. Debido a ello es de interés científico y médico conocer a detalle cómo se comunican las bacterias en sus particulares grupos de "WhatsApp" para generar nuevo conocimiento que contribuya con el establecimiento de tratamientos terapeúticos más eficientes para el combate de las infecciones microbianas.

\section{Referencias}

* Ahator, S. D., y Zhang, L. (2019). Small Is Mighty_Chemical Communication Systems in Pseudomonas aeruginosa. Annual review of microbiology, 73, 559-578. https://doi.org/10.1146/annurev-micro-020518-120044

* El rincón curioso. (2018, 19 de septiembre). -5 PLAYAS INCREÍBLES - que se ILUMINAN en la OSCURIDAD [video]. YouTube. https://youtu.be/Jg_d9orAG1o

*osthuizen, J. (2013). [Pseudomonas aeruginosa bacteria]. Centers for Disease Control. https://phil.cdc.gov/details.aspx?pid=16876

* Lee, J., y Zhang, L. (2015). The hierarchy quorum sensing network in Pseudomonas aeruginosa. Protein \& Cell, 6(1), 26-41. https://doi.org/10.1007/s13238-014-0100-x

* Lee, J., Wu, J., Deng, Y., Wang, J., Wang, C., Wang, J., Chang, C., Dong, Y., Williams, P. y Zhang, L. H. (2013). A cell-cell communication signal integrates quorum sensing and stress response. Nature chemical biology, 9(5), 339-343. https://doi. org/10.1038/nchembio.1225

* Marquina Díaz, D., y Santos de la Sen, A. (2011). Sistemas de quorum sensing en bacterias. Reduca (Biología), 3(5), 39-55. http://revistareduca.es/index.php/ biologia/article/view/820/835

* Moradali, M. F., Ghods, S., y Rehm, B. H. (2017). Pseudomonas aeruginosa lifestyle: a paradigm for adaptation, survival, and persistence. Frontiers in cellular and infection microbiology, 7(39). https://doi.org/10.3389/fcimb.2017.00039

* Papenfort, K., y Bassler, B. L. (2016). Quorum sensing signal-response systems in Gram-negative bacteria. Nature Reviews Microbiology, 14(9), 576-588. https://doi. org/10.1038/nrmicro.2016.89

* Soberón, G. (2001). Pseudomonas aeruginosa. En E. Martínez Romero y J. C. Martínez Romero (Eds.), Microbiología en línea (cap. 3). http://www.biblioweb.tic. unam.mx/libros/microbios/Cap3/.

\section{Cómo CITAR ESTE ARTículo}

* DíazPérez, Sharel Pamelay Campos García,Jesús. (2021, mayo-junio). Comunicación entre bacterias: el WhatsApp de Pseudomonas aeruginosa. Revista Digital Universitaria (RDU), 22(3). http://doi.org/10.22201/cuaieed.16076079e.2021.22.3.7 